\title{
Características estruturais e produção de forragem do capim-piatã submetido a regimes de desfolhação intermitente
}

\author{
[Structural characteristics and forage production of piata grass submitted \\ to intermittent defoliation management] \\ G.O. Rocha ${ }^{1}$, F.H.M. Chizzotti ${ }^{2}$, M.E.R. Santos $^{3}$, B.M.L. Sousa ${ }^{4}$, \\ D.M. Fonseca ${ }^{2}$, B.H.R. Carvalho ${ }^{1}$ \\ ${ }^{1}$ Aluno de Pós-graduação - Universidade Federal de Uberlândia - Uberlândia, MG \\ ${ }^{2}$ Universidade Federal de Viçosa - Viçosa, MG \\ ${ }^{3}$ Universidade Federal de Uberlândia - Uberlândia, MG \\ ${ }^{4}$ Universidade Federal de Sergipe - São Cristóvão, SE
}

\begin{abstract}
RESUMO
Objetivou-se avaliar as características estruturais e a produção de forragem do capim-piatã submetido à combinação de duas frequências de corte (95\% e máxima interceptação de luz pelo dossel forrageiro, $\mathrm{IL}_{\max }$ ) e duas alturas pós-corte $(15$ e $20 \mathrm{~cm})$, no período de janeiro de 2012 a março de 2013. O delineamento utilizado foi em blocos ao acaso, com três repetições, em esquema fatorial $2 \times 2$, totalizando 12 unidades experimentais de $14 \mathrm{~m}^{2}$ cada. Foram avaliadas as seguintes variáveis-respostas: altura do dossel no précorte, intervalo de corte, índice de área foliar pré e pós-corte, taxa de produção de forragem e as percentagens de colmo, folha e forragem morta na forragem produzida. A altura pré-corte decresceu durante o experimento (de 65,81 para $34,03 \mathrm{~cm}$ ), sendo a menor altura observada no dossel sob alta frequência de desfolhação (95\% de IL). A taxa de produção de forragem foi maior nas épocas favoráveis ao crescimento da gramínea forrageira. As percentagens de folha, colmo e forragem morta foram semelhantes entre as frequências de corte. Assim, o capim-piatã sob manejo de desfolhação intermitente pode ser colhido com qualquer combinação de frequências de corte de $95 \%$ e ou máxima interceptação de luz, e alturas pós-corte de 15 ou $20 \mathrm{~cm}$.
\end{abstract}

Palavras-chave: altura, estrutura do dossel, índice de área foliar, Urochloa brizantha

\begin{abstract}
The objective of this study was to evaluate the structural characteristics and forage production of the piatã grass submitted to the combination of two cutting frequencies $(95 \%$ and maximum interception of light by the forage canopy, $\left.I L_{\max }\right)$ and two post cutting heights $(15$ and $20 \mathrm{~cm})$ in the period from January 2012 to March 2013. The design was a randomized complete block with three replications, in a $2 \times 2$ factorial scheme, totaling 12 experimental units of $14 \mathrm{~m}^{2}$ each. The following variables were evaluated: pre-cut canopy height, cut interval, pre and post-cut leaf area index, forage yield rate, and percentage of stem, leaf and dead forage in the forage produced. The pre-cut height decreased during the experiment (from 65.81 to $34.03 \mathrm{~cm}$ ), with the lowest height observed in the canopy under high frequency of defoliation (95\% IL). The rate of forage production was higher in the seasons favorable to forage grass growth. The percentages of leaf, stem and dead fodder were similar between cut-off frequencies. Thus, piatã grass under intermittent defoliation management can be harvested with any combination of $95 \%$ and maximum light interception cut frequencies, and post cutting heights of 15 or $20 \mathrm{~cm}$.
\end{abstract}

Keywords: canopy structural, height, leaf area index, Urochloa brizantha

Recebido em 29 de abril de 2019

Aceito em 1 de outubro de 2019

E-mail: gabriel.o.rocha@hotmail.com.br 


\section{INTRODUÇÃO}

A estrutura do pasto pode ser definida como a distribuição ou o arranjo dos componentes da parte aérea da planta dentro de uma comunidade (Laca and Lemaire, 2000). Várias características são utilizadas para descrever a estrutura de um pasto, tais como altura, densidade populacional de perfilhos (Montagner et al., 2012), densidade de forragem (Nantes et al., 2013), índice de área foliar (IAF) e ângulo da folhagem (Difante et al., 2009 a e b).

No tocante à planta forrageira, a estrutura do pasto influencia o microclima (luminosidade, umidade, temperatura, ventilação, etc.) no interior do dossel, o que desencadeia modificações no desenvolvimento do pasto (Chapman e Lemaire, 1993). Com relação ao animal, a estrutura do pasto influencia o comportamento ingestivo, o consumo e o desempenho (Carvalho et al., 2013).

Dessa forma, a estrutura do pasto é característica central e determinante das respostas, tanto de plantas como de animais, razão pela qual é estudada e considerada para o estabelecimento de práticas de manejo do pastejo. Realmente, as pesquisas recentes têm demonstrado que o controle da estrutura do dossel forrageiro pode resultar em efeitos positivos sobre a persistência do pasto, a eficiência de pastejo e a produção animal em pastagens (Difante et al., 2009a, b; Pedreira et al., 2007; Giacomini et al., 2009; Silveira et al., 2013).

Em condições de lotação intermitente, o critério de interrupção da rebrotação, quando o dossel forrageiro intercepta $95 \%$ da luz, tem se mostrado adequado para reduzir o alongamento do colmo e a senescência, sem comprometer o crescimento foliar (Euclides et al., 2014). Quanto à intensidade da desfolhação, as alturas de resíduo pós-pastejo também têm sido empregadas como critério prático para o controle da estrutura do pasto (Euclides et al., 2014). Entretanto, informações acerca de metas de manejo definidas com base na interceptação de luz pelo dossel e na altura de resíduo forrageiro do capim-piatã sob lotação intermitente ainda não existem. Nesse contexto, objetivou-se avaliar as características estruturais e a produção de forragem do capim-piatã submetido às combinações de duas frequências e duas intensidades de desfolhação.

\section{MATERIAL E MÉTODOS}

O experimento foi conduzido no Setor Forragicultura da Universidade Federal de Viçosa (UFV), em Viçosa, MG (latitude $20^{\circ} 45^{\prime} \mathrm{S}$, longitude $42^{\circ} 51^{\prime} \mathrm{W}$ e altitude de $651 \mathrm{~m}$ ), de janeiro de 2012 a março de 2013. O clima da região é do tipo Cwa subtropical, com duas estações do ano bem definidas, verão quente e chuvoso, e inverno frio e seco (Köppen,1948). A pluviosidade média anual corresponde a $1340 \mathrm{~mm}$, com umidade relativa média do ar de $80 \%$. Os dados climáticos do período experimental foram coletados em estação meteorológica da UFV, distante aproximadamente 1000 metros do local do experimento (Fig. 1).

O solo da área experimental é classificado como Argissolo Vermelho-Amarelo (Sistema..., 1999). No início do experimento, foram coletadas amostras de solo na profundidade de 0 a $20 \mathrm{~cm}$, para análise do nível de fertilidade. Os resultados foram: $\mathrm{pH}$ em $\mathrm{H}_{2} \mathrm{O}, 5,09$; $\mathrm{P}, 1,5 \mathrm{mg} \mathrm{dm}^{-3}$; $\mathrm{K}, 29 \mathrm{mg}$ $\mathrm{dm}^{-3} ; \mathrm{Ca}^{+2}, 2,7 \mathrm{cmol}_{\mathrm{c}} \mathrm{dm}^{-3} ; \mathrm{Mg}^{+2}, 0,6 \mathrm{cmol}_{\mathrm{c}} \mathrm{dm}^{-3}$; $\mathrm{Al}^{+3}, 0,1 \mathrm{cmol}_{\mathrm{c}} \mathrm{dm}^{-3} ; \mathrm{H}+\mathrm{Al}, 5,5 \mathrm{cmol}_{\mathrm{c}} \mathrm{dm}^{-3} ; \mathrm{SB}$, $3,37 \mathrm{cmol}_{\mathrm{c}} \mathrm{dm}^{-3}$; t, 3,47 $\mathrm{cmol}_{\mathrm{c}} \mathrm{dm}^{-3}$; T, 8,87 $\mathrm{cmol}_{\mathrm{c}}$ $\mathrm{dm}^{-3} ; \mathrm{V}, 38 \%$; m, 29\%. Com base nesses resultados, as adubações foram realizadas seguindo as diretrizes do CFSEMG (Ribeiro et al., 1999) para um sistema de médio nível tecnológico. No dia 15 de janeiro de 2012, foi realizada uma única aplicação de $50 \mathrm{~kg} \mathrm{ha}^{-1}$ de $\mathrm{N}$, de $\mathrm{P}_{2} \mathrm{O}_{5}$ e de $\mathrm{K}_{2} \mathrm{O}$, na forma de sulfato de amônio, superfosfato simples e cloreto de potássio, respectivamente. Adicionalmente, $150 \mathrm{~kg} \mathrm{ha}^{-1} \mathrm{de}$ $\mathrm{N}$ foram aplicados entre janeiro e março de 2012, de forma parcelada e em quantidade proporcional ao período de descanso, sempre após os cortes dos dosséis.

Em 06 de outubro de 2012, foram aplicados $15 \mathrm{~kg}$ ha $^{-1}$ de $\mathrm{P}_{2} \mathrm{O}_{5}, 60 \mathrm{~kg} \mathrm{ha}^{-1}$ de $\mathrm{K}_{2} \mathrm{O}$ e $60 \mathrm{~kg} \mathrm{ha}^{-1}$ de $\mathrm{N}$, na forma de adubo formulado 20-05-20 (20\% de $\mathrm{N}, 5 \%$ de $\mathrm{P}_{2} \mathrm{O}_{5}$ e $20 \%$ de $\mathrm{K}_{2} \mathrm{O}$ ). Adicionalmente, mais $150 \mathrm{~kg} \mathrm{ha}^{-1}$ de $\mathrm{N}$ foram distribuídos às parcelas entre outubro de 2012 a março de 2013, de forma semelhante à adubação descrita no verão anterior. 


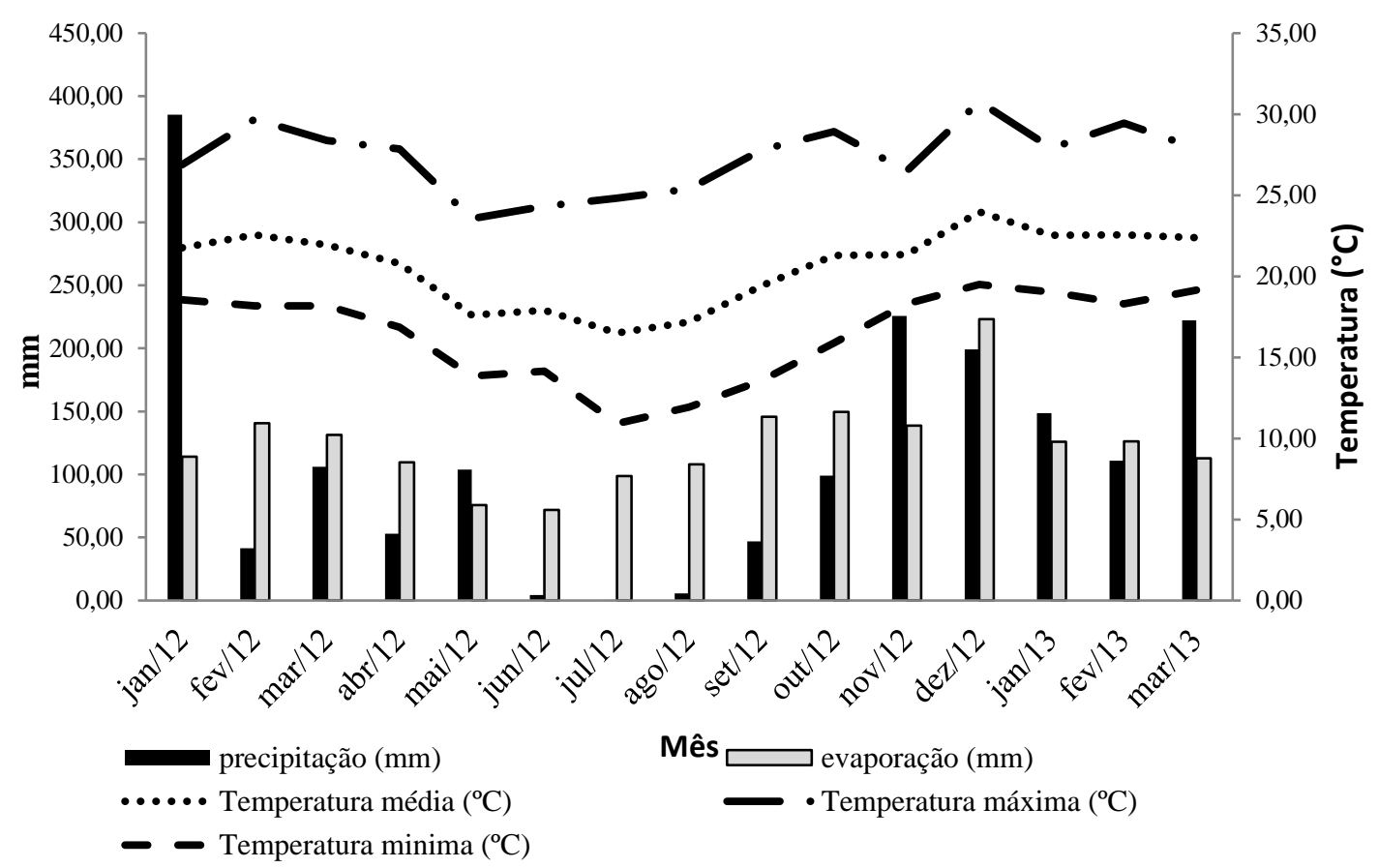

Figura 1. Precipitação pluviométrica e evaporação acumuladas mensais $(\mathrm{mm})$, temperaturas mínimas, média e máxima $\left({ }^{\circ} \mathrm{C}\right)$, durante o período experimental.

A espécie forrageira avaliada foi a Urochloa brizantha cv. Piatã, estabelecida em 2007. O dossel forrageiro estava em crescimento livre por seis meses antes da demarcação das unidades experimentais, que ocorreu em 13 de janeiro de 2012. Nessa data foi realizado o corte, com roçadeira costal, das plantas, nas alturas almejadas.

Foram avaliadas combinações de duas frequências de corte (95\% e máxima interceptação de luz pelo dossel, IL) e duas alturas pós-corte (15 ou $20 \mathrm{~cm}$, APC), em um arranjo fatorial $2 \times 2$, correspondendo a quatro regimes de desfolhação: 95/15 (95\% de IL e 15cm de APC), 95/20 (95\% de IL e $20 \mathrm{~cm}$ de APC), IL max $_{\text {max }} / 15$ (máxima IL e APC de $15 \mathrm{~cm}$ ) e $\mathrm{IL}_{\max } / 20$ (máxima IL e APC de $20 \mathrm{~cm}$ ). O delineamento foi em blocos ao acaso, com três repetições, perfazendo 12 unidades experimentais de $14 \mathrm{~m}^{2}(4,0 \times 3,5 \mathrm{~m})$. O dossel foi cortado quando as metas pré-corte de interceptação luminosa foram alcançadas. Para isso, foi usada uma roçadeira costal e uma régua graduada em centímetros.

O acompanhamento do nível da interceptação de luz pelo dossel, bem como o índice de área de foliar, foi realizado utilizando-se o analisador de dossel LAI-2000 da LI-COR ${ }^{\circledR} \quad$ (LI-COR, Linconln, Nebraska, EUA). O monitoramento da IL pelo dossel foi realizado no pós-corte, semanalmente, durante a rebrotação dos pastos até a IL de $90 \%$, e, a partir desse ponto, a cada dois dias, até que as metas de 95 e máxima IL fossem atingidas. A IL foi considerada máxima quando seu valor não aumentou após três medições consecutivas. As medições foram efetuadas em duas estações por unidade experimental, sendo cada estação correspondente a uma leitura em um ponto acima do dossel e cinco pontos rente ao solo, distribuídos aleatoriamente na unidade experimental. A altura do pasto foi obtida no précorte, com o uso de uma régua graduada em centímetros, e 10 medições por parcela foram usadas para se obter a média. A coleta desses dados foi aleatória na parcela.

Um retângulo de armação metálica de $1,05 \mathrm{~m} \mathrm{x}$ $0,66 \mathrm{~m}\left(0,7 \mathrm{~m}^{2}\right)$ foi usado para a colheita de amostra da forragem produzida. Realizada no précorte, toda a massa de forragem acima da meta de altura pós-corte para a parcela, que estivesse dentro da área da armação, foi cortada com o auxílio de uma pequena foice, em um único ponto por unidade experimental, representativo da altura média do dossel. A forragem colhida foi 
armazenada em sacos plásticos identificados, levados ao laboratório e pesados. Essa amostra foi, então, dividida em duas subamostras, uma das quais foi seca em estufa de ventilação forçada a $55^{\circ} \mathrm{C}$, por 72 horas, para quantificação do teor de matéria seca da forragem. Dessa forma, foi possível calcular a massa de forragem $\left(\mathrm{kg} \mathrm{ha}^{-1} \mathrm{de}\right.$ MS), multiplicando-se o teor de matéria seca pelo peso total da amostra colhida. A outra subamostra foi separada em seus componentes morfológicos (lâmina foliar viva, colmo vivo e forragem morta), os quais foram levados para estufa de ventilação forçada a $55^{\circ} \mathrm{C}$, por 72 horas, e pesados. Esses dados foram usados para quantificar o percentual de cada componente na massa de forragem.

A taxa de produção ( $\mathrm{kg} \mathrm{ha} \mathrm{h}^{-1} \mathrm{dia}^{-1}$ de $\mathrm{MS}$ ) foi calculada pela divisão da massa de forragem pelo intervalo de corte (dia) correspondente a cada ciclo de produção. Os dados foram organizados em épocas do ano, de modo que os padrões de resposta fossem semelhantes dentro das épocas. Os valores médios das variáveis respostas em cada época foram calculados pela média ponderada, considerando-se o número de dias do ciclo de rebrotação em cada época. Desse modo, quatro estações do ano foram determinadas: verão 1, de janeiro/2012 a março/2012; outono, de abril/2012 a junho/2012; inverno mais início de primavera (IIP), de julho/2012 a novembro/2012; fim de primavera e verão 2 (FPV2), de dezembro/2012 a março/2013.

Foi utilizado, para análise estatística, o procedimento "PROC MIXED", do programa SAS (1990), versão 9.0, para Windows ${ }^{\circledR}$. Para a escolha da matriz de covariância, utilizou-se o critério de Akaike (Wolfinger, 1993). A interceptação de luz (IL), as alturas residuais póscorte, as épocas do ano e suas interações foram consideradas efeitos fixos, enquanto os blocos, efeito aleatório (Littel et al., 1996). Todos os dados foram previamente testados para assegurar as prerrogativas básicas para análise de variância. As médias para os tratamentos foram obtidas através do procedimento "LSMEANS", e a comparação foi feita por meio do teste de Tukey, com a probabilidade do erro tipo I de $10 \%$.

\section{RESULTADOS E DISCUSSÃO}

A altura pré-corte foi influenciada pela interação entre a frequência de corte e a estação do ano
( $\mathrm{P}<0,0001)$, de modo que o dossel forrageiro sob menor frequência de corte $\left(\mathrm{IL}_{\max }\right)$ apresentou maior altura em todas as épocas (Tab. 1). O maior tempo de rebrotação dos pastos manejados com $\mathrm{IL}_{\max }$ acentuou a competição por luz entre os perfilhos. Como consequência, houve maior alongamento de colmo para alocar as novas folhas no topo do dossel, onde há maior incidência de luz (Lemaire, 2001), aumentando, assim, a altura do pasto.

A altura pré-corte do dossel manejado com $95 \%$ de interceptação de luz (IL95) foi decrescente entre as épocas do ano, com maior valor no verão $1 \mathrm{e}$ menor no fim de primavera e verão 2 (FPV2) (Tab. 1). Provavelmente, isso ocorreu em função da adaptação da planta ao manejo. Antes do experimento, os dosséis forrageiros estavam em crescimento livre, com baixa densidade populacional de perfilhos, sendo esses longos e pesados, com muitos em estádio reprodutivo. Com o início do experimento, os cortes removeram grande porção da parte aérea da planta, aumentando a incidência de luz na base do dossel e estimulando o perfilhamento. Assim, ao longo das épocas, a gramínea foi se adaptando aos manejos experimentais, substituindo os poucos perfilhos longos por maior número de perfilhos pequenos, com consequente diminuição da altura do pasto (Sbrissia e Silva, 2008).

O intervalo de corte foi influenciado pela frequência de desfolhação apenas nos períodos favoráveis ao crescimento da planta forrageira, o verão 1 e $\quad$ o FPV2, quando houve maior pluviosidade e temperatura média (Fig. 1), de modo que a $\mathrm{IL}_{\max }$ resultou em maior intervalo de corte do que a IL 95 (Tab. 1), pois é necessário mais tempo para que o dossel produza um maior índice de área foliar (IAF), capaz de interceptar mais luz, resultado semelhante ao de Pedreira et al. (2007) com capim-xaraés. No outono e inverno e início de primavera (IIP), a frequência de desfolhação não influenciou o intervalo de corte, pois as condições ambientais foram muito limitantes (Fig. 1). Resultados semelhantes foram observados por Carnevali et al. (2006), com capim-mombaça; Barbosa et al. (2007), com capim-tanzânia; e Silveira et al. (2013), com capim-mulato. 
Tabela 1. Altura pré-corte, intervalo de corte, índice de área foliar (IAF) pré e pós-corte e percentagem de lâmina foliar e colmo vivos de capim-piatã submetido a duas frequências de desfolhação durante as épocas do ano, de janeiro de 2012 a março de 2013

\begin{tabular}{|c|c|c|c|}
\hline \multirow{2}{*}{ Época do ano } & \multicolumn{2}{|c|}{ Interceptação de luz (\%) } & \multirow{2}{*}{ EPM } \\
\hline & IL95 & $\mathrm{IL}_{\max }$ & \\
\hline \multicolumn{4}{|c|}{ Altura pré-corte $(\mathrm{cm})$} \\
\hline Verão 1 & $50,36 \mathrm{Ab}$ & $65,81 \mathrm{Aa}$ & 2,41 \\
\hline Outono & $40,71 \mathrm{Bb}$ & $48,03 \mathrm{Ca}$ & 1,09 \\
\hline IIP & $37,86 \mathrm{BCb}$ & $66,81 \mathrm{Aa}$ & 3,67 \\
\hline FPV2 & $34,03 \mathrm{Cb}$ & $50,73 \mathrm{Ba}$ & 0,79 \\
\hline \multicolumn{4}{|c|}{ Intervalo de corte (dia) } \\
\hline Verão 1 & $62,24 \mathrm{Bb}$ & $80,83 \mathrm{Ba}$ & 1,00 \\
\hline Outono & $90,75 \mathrm{Ba}$ & $61,06 \mathrm{CBa}$ & 9,50 \\
\hline IIP & $171,76 \mathrm{Aa}$ & $145,31 \mathrm{Aa}$ & 7,89 \\
\hline FPV2 & $28,08 \mathrm{Cb}$ & $51,89 \mathrm{Ca}$ & 2,37 \\
\hline \multicolumn{4}{|c|}{ IAF pré-corte } \\
\hline Verão 1 & $3,73 \mathrm{Ab}$ & $4,84 \mathrm{Ca}$ & 0,11 \\
\hline Outono & $3,96 \mathrm{Ab}$ & $5,38 \mathrm{Ba}$ & 0,11 \\
\hline IIP & $4,04 \mathrm{Ab}$ & $5,85 \mathrm{Aa}$ & 0,11 \\
\hline FPV2 & $3,94 \mathrm{Ab}$ & $5,66 \mathrm{ABa}$ & 0,11 \\
\hline \multicolumn{4}{|c|}{ IAF pós-corte } \\
\hline Verão 1 & $1,18 \mathrm{Ca}$ & $1,19 \mathrm{Ba}$ & 0,082 \\
\hline Outono & $1,70 \mathrm{Ba}$ & $1,79 \mathrm{Aa}$ & 0,082 \\
\hline IIP & $1,92 \mathrm{ABa}$ & $1,89 \mathrm{Aa}$ & 0,082 \\
\hline FPV2 & $2,32 \mathrm{Aa}$ & $1,93 \mathrm{Ab}$ & 0,082 \\
\hline \multicolumn{4}{|c|}{ Lâmina foliar viva $(\%)$} \\
\hline Verão 1 & $81,24 \mathrm{Aa}$ & $68,69 \mathrm{Ba}$ & 3,71 \\
\hline Outono & $84,67 \mathrm{Aa}$ & $87,91 \mathrm{Aa}$ & 2,56 \\
\hline IIP & $79,20 \mathrm{Aa}$ & $69.21 \mathrm{Ba}$ & 3,29 \\
\hline FPV2 & $81,35 \mathrm{Aa}$ & $78,44 \mathrm{Ba}$ & 1,99 \\
\hline \multicolumn{4}{|c|}{ Colmo vivo $(\%)$} \\
\hline Verão 1 & $14,50 \mathrm{Ab}$ & $27,48 \mathrm{Aa}$ & 1,91 \\
\hline Outono & $12,13 \mathrm{Aa}$ & $8,00 \mathrm{Ca}$ & 1,91 \\
\hline IIP & $17,76 \mathrm{Aa}$ & $25,39 \mathrm{BCa}$ & 1,91 \\
\hline FPV2 & $16,11 \mathrm{Aa}$ & $18,79 \mathrm{Ba}$ & 1,91 \\
\hline
\end{tabular}

IL95: condição em que o dossel intercepta $95 \%$ da luz incidente; $\mathrm{IL}_{\max }$ : condição em que o dossel tem a máxima interceptação da luz incidente. EPM: erro-padrão da média. Para cada variável, médias seguidas pela mesma letra, maiúscula na coluna e minúscula na linha, não diferem $(\mathrm{P}>0,10)$ pelo teste de Tukey.

Durante o verão 1 e o FPV2, quando as condições ambientais foram favoráveis ao crescimento vegetal e houve adubação, o intervalo de corte foi menor. Nota-se que no outono obteve-se intervalo de corte semelhante ao do verão 1 , o que pode ser explicado pela incomum e alta incidência de chuvas que houve nesse período (Fig. 1), fato que provavelmente propiciou o aproveitamento dos fatores ambientais (nutrientes e luminosidade) e permitiu maior crescimento do dossel forrageiro. Adicionalmente, no início do experimento, o processo de adaptação do capim-piatã ao novo manejo experimental pode ter demorado e resultado em intervalo de corte maior para atingir as metas de interceptação de luz (IL), contribuindo para que seus valores fossem semelhantes ao do outono.

O IAF pré-corte foi influenciado pela interação entre a frequência de corte e a época do ano $(\mathrm{P}=0,0172)$ e entre a frequência de corte e a altura pós-corte $(\mathrm{P}=0,0258)$ (Tab. 1, 2). O IAF foi maior na menor frequência de corte ( $\left.\mathrm{IL}_{\max }\right)$, em todas as épocas do ano (Tab. 1), e nas duas alturas póscorte (Tab. 2). O maior período de rebrotação necessário para o dossel alcançar a $\mathrm{IL}_{\max }$ resultou em mais tempo para utilizar os recursos do ambiente para o crescimento, o que aumentou o IAF pré-corte. 
Tabela 2. Índice de área foliar pré-corte e taxa de produção de forragem em dosséis de capim-piatã submetidos a duas alturas pós-corte e duas frequências de corte, de janeiro de 2012 a março de 2013

\begin{tabular}{|c|c|c|c|}
\hline \multirow{2}{*}{$\begin{array}{l}\text { Altura pós-corte } \\
(\mathrm{cm})\end{array}$} & \multicolumn{2}{|c|}{ Interceptação de luz (\%) } & \multirow{2}{*}{ EPM } \\
\hline & IL95 & $\mathrm{IL}_{\max }$ & \\
\hline \multicolumn{4}{|c|}{ IAF pré-corte } \\
\hline 15 & $3,98 \mathrm{Ab}$ & $5,30 \mathrm{Aa}$ & 0,078 \\
\hline 20 & $3,86 \mathrm{Ab}$ & $5,56 \mathrm{Aa}$ & 0,078 \\
\hline \multicolumn{4}{|c|}{ Taxa de produção $\left(\mathrm{kg} \mathrm{ha}^{-1} \mathrm{dia}^{-1}\right.$ de $\left.\mathrm{MS}\right)$} \\
\hline 15 & $63,42 \mathrm{Aa}$ & $64,46 \mathrm{Aa}$ & 2,91 \\
\hline 20 & $59,52 \mathrm{Ab}$ & $70,56 \mathrm{Aa}$ & 2,91 \\
\hline
\end{tabular}

IL95: condição em que o dossel intercepta $95 \%$ da luz incidente; $\mathrm{IL}_{\max }$ : condição em que o dossel tem a máxima interceptação da luz incidente. EPM: erro-padrão da média. Para cada variável, médias seguidas pela mesma letra, maiúscula na coluna e minúscula na linha, não diferem $(\mathrm{P}>0,10)$ pelo texto de Tukey.

Vale salientar que o manejo do capim-piatã sob $\mathrm{IL}_{95}$ gerou pequena variação do IAF no pré-corte (Tab. 1), com diferença entre o menor e o maior valor de apenas $7,67 \%$. Devido a essa pequena variação sob as diferentes condições de crescimento às quais a forrageira foi submetida ao longo do ano, o IAF, quando o dossel intercepta 95\% da luz incidente, ou IAF "crítico" (Brougham, 1956), pode ser um parâmetro para o manejo do pastejo.

O manejo do pasto com menor frequência de corte faz com que se estabeleça uma competição intraespecífica por fatores ambientais de crescimento, como água, luz e nutrientes. Para o manejo de cortes intermitentes, a competição por luz fica mais acentuada a partir de $95 \%$ de IL, quando os perfilhos tendem a alongar os entrenós, aumentando de tamanho (Sbrissia e Silva, 2008), de forma a posicionar as novas folhas em condições de maior luminosidade (Chapman e Lemaire, 1993), enquanto aquelas presentes na base do dossel tendem a morrer devido ao sombreamento (Duru e Ducrocq, 2000). Logo, espera-se que, em pastos manejados com cortes intermitentes e menos frequentes, o IAF remanescente após a colheita seja menor do que naqueles dosséis manejados com maiores frequências de corte, pois a maior parte das folhas vivas, o principal componente do IAF, está presente nas partes mais altas do dossel manejado sob desfolhações menos frequentes. Esse fato pode justificar o inferior IAF pós-corte do capimpiatã submetido à menor frequência de desfolhação ( $\mathrm{IL}_{\max }$ ), em comparação àquele sob IL95, durante o FPV2 (Tab. 1).

O crescente IAF pós-corte do início para o final do experimento observado entre as frequências
(Tab. 1) e as alturas pós-corte (Tab. 3) pode ter ocorrido em razão da compensação tamanho/densidade de perfilhos, bem como da redistribuição das folhas no perfil vertical do dossel, que se modificaram no decorrer do período experimental. Antes do experimento, o pasto estava em crescimento livre, com baixa densidade de perfilhos, e esses eram grandes, mas desenvolveu para um dossel com alta densidade populacional de perfilhos menores ao longo do período experimental.

O IAF pós-corte foi maior no dossel com maior altura pós-corte, pois cortes mais lenientes retiram menor quantidade da parte aérea da planta, deixando resíduo com maior número de folhas e, consequentemente, maior IAF. Resultado semelhante foi observado por Sousa et al. (2011), em trabalho com Brachiaria brizantha cv. Xaraés manejadas com três alturas pós-corte $(15 \mathrm{~cm}$, $20 \mathrm{~cm}$ e $25 \mathrm{~cm}$ ), quando o dossel interceptava $95 \%$ de IL. Nesse trabalho, a interceptação de luz e o índice de área foliar pós-corte apresentaram valores crescentes, com menor valor na menor altura de $15 \mathrm{~cm}$.

A interceptação de luz pelo dossel após o corte está positivamente relacionada com o IAF remanescente (Borges et al., 2011; Sousa et al., 2011). Dessa forma, como os dosséis sob maior frequência de corte e maior altura pós-corte apresentaram maior IAF pós-corte (Tab. 1, 3), é natural que eles também apresentem maior interceptação de luz após o corte (Tab. 4). Nesse mesmo sentido, com relação às épocas do ano, a IL pós-corte foi crescente ao longo do experimento (Tab. 4), tal como ocorreu com o IAF pós-corte (Tab. 1). 
Tabela 3. Índice de área foliar pós-corte em pastos de capim-piatã submetidos a duas alturas pós-corte e duas frequências de corte, de janeiro de 2012 a março de 2013

\begin{tabular}{lccc}
\hline \multirow{2}{*}{ Época do ano } & \multicolumn{2}{c}{ Altura pós-corte $(\mathrm{cm})$} & \multirow{2}{*}{ EPM } \\
\cline { 2 - 4 } & 15 & 20 & 0,082 \\
Verão 1 & $1,04 \mathrm{Ba}$ & $1.34 \mathrm{Ca}$ & 0,082 \\
Outono & $1,54 \mathrm{Ab}$ & $2.01 \mathrm{Ba}$ & 0,082 \\
Inv/InPri & $1,46 \mathrm{Ab}$ & $2.35 \mathrm{ABa}$ & 0,082 \\
FPV2 & $1,81 \mathrm{Ab}$ & $2.45 \mathrm{Aa}$ & \\
\hline
\end{tabular}

IL95: condição em que o dossel intercepta 95\% da luz incidente; $\mathrm{IL}_{\max }$ : condição em que o dossel tem a máxima interceptação da luz incidente. EPM: erro-padrão da média. Médias seguidas pela mesma letra, maiúscula na coluna e minúscula na linha, não diferem $(\mathrm{P}>0,10)$ pelo teste de Tukey.

Tabela 4. Interceptação de luz no pós-corte em dosséis de capim-piatã submetidos a duas frequências de desfolhação, duas alturas pós-corte, em quatro épocas do ano, de janeiro de 2012 a março de 2013

\begin{tabular}{ll|ll|llll}
\hline $\begin{array}{l}\text { Interceptação de luz } \\
(\%)\end{array}$ & $\begin{array}{l}\text { Altura pós-corte } \\
(\mathrm{cm})\end{array}$ & & Época do ano & & \\
\hline $\mathrm{IL}_{95}$ & $\mathrm{IL}_{\max }$ & 15 & 20 & Verão 1 & Outono & IIP & FPV2 \\
$72,95 \mathrm{a}$ & $70,03 \mathrm{~b}$ & $66,15 \mathrm{~b}$ & $76,83 \mathrm{a}$ & $58,94 \mathrm{c}$ & $73,22 \mathrm{~b}$ & $74,67 \mathrm{ab}$ & $79,16 \mathrm{a}$ \\
\hline
\end{tabular}

IL95: condição em que o dossel intercepta 95\% da luz incidente; ILmax: condição em que o dossel tem a máxima interceptação da luz incidente. Erro-padrão da média da interceptação de luz e da altura pós-corte igual a 0,87, e da época do ano 1,41. Para cada fator, médias seguidas pela mesma letra minúscula não diferem $(\mathrm{P}>0,10)$ pelo teste de Tukey.

A taxa de produção de forragem do capim-piatã variou com a interação entre a frequência de corte e a altura pós-corte $(\mathrm{P}=0,0992)$ e com as estações do ano $(\mathrm{P}<0,0001)$. A interceptação de luz é premissa para a realização da fotossíntese e, consequentemente, para a produção de forragem (Taiz e Zeiger, 2009). Esse provavelmente foi o motivo que levou à maior taxa de produção de forragem nos dosséis manejados com altura residual de $20 \mathrm{~cm}$ e com IL $_{\max }$, em comparação aos dosséis sob 95\% de IL (Tab. 2).

As condições ambientais têm influência no crescimento e no desenvolvimento das forrageiras. As épocas com restrição de um ou mais fatores de crescimento podem limitar o desenvolvimento, sendo essa a principal causa da variação da taxa de produção de forragem ao longo das estações do ano (Silveira et al., 2013). A menor taxa de produção de forragem ocorreu no IIP $\left(36,95 \mathrm{~kg} \mathrm{ha}^{-1} \mathrm{dia}^{-1}\right.$ de MS), com valores intermediários e semelhantes no verão $1(62,78 \mathrm{~kg}$ $\mathrm{ha}^{-1} \mathrm{dia}^{-1}$ de MS) e no outono $\left(55,37 \mathrm{~kg} \mathrm{ha}^{-1} \mathrm{dia}^{-1}\right.$ de MS) e maior valor no FPV2 $\left(102,89 \mathrm{~kg} \mathrm{ha}^{-1} \mathrm{dia}^{-}\right.$ 1 de MS). No IIP, as restrições de água e de temperatura foram mais acentuadas (Fig. 1), sendo maiores no outono e verão 1 . Nessa época, apesar da alta pluviosidade, as chuvas foram mal distribuídas, com veranico no mês de fevereiro e baixa quantidade de chuvas em abril (Fig. 1). Adicionalmente, no outono, houve redução da temperatura (Fig. 1), o que diminui o crescimento das gramíneas tropicais (Silveira et al., 2013; Duru e Ducrocq, 2000). De modo contrário, o FPV2 foi a época do ano que reuniu as melhores condições ambientais para o crescimento vegetal, o que proporcionou a maior taxa de produção de forragem.

A percentagem de lâmina foliar viva foi influenciada pela interação entre as épocas do ano e a frequência de corte $(\mathrm{P}<0,0001)$. A maior percentagem de folha viva no dossel sob a menor frequência de corte ( $\mathrm{IL}_{\max }$ ) ocorreu no outono. Porém, não houve diferença entre as frequências de corte para essa característica (Tab. 1) nas demais épocas do ano.

Para a percentagem de colmo vivo na composição da forragem produzida, houve efeito da interação entre a frequência de corte e a época do ano $(\mathrm{P}=0,00013)$. Houve menor percentagem de colmo no dossel manejado com $\mathrm{IL}_{95}$, em relação àquele sob $\mathrm{IL}_{\max }$ apenas durante o verão 1 . No dossel manejado com $\mathrm{IL}_{\max }$, a percentagem de colmo vivo foi menor no outono do que nas demais épocas do ano. Já no dossel manejado com IL95, a percentagem de colmo vivo não variou entre as épocas do ano (Tab. 1).

A percentagem de forragem morta não foi influenciada por nenhum fator, apresentando 
média de $3,56 \%$ na composição da forragem produzida. O mínimo efeito das frequências de corte avaliadas sobre as percentagens dos componentes morfológicos (Tab. 1) provavelmente ocorreu, pois a massa de forragem amostrada correspondeu àquelas acima da altura pós-corte. Assim, os componentes que compõem a maior parte dos estratos inferiores do dossel, como colmo vivo e forragem morta, não foram colhidos. Entretanto, a massa de forragem colhida, que representa o estrato ofertado ao animal sob lotação intermitente, apresentou alta percentagem de folha viva, mas baixa de colmo vivo e forragem morta, o que é desejável para produção animal.

A variação das características estruturais do capim-piatã ao longo do período experimental (Tab. 1, 3), mesmo com a manutenção do mesmo manejo da desfolhação, indica que os dosséis forrageiros passaram por um período de adaptação relativamente longo, o que pode ter impedido a manifestação de possíveis diferenças entre as estratégias de desfolhação avaliadas. Nesse contexto, é recomendável que os dosséis passem por maior período de adaptação, antes do início das avaliações das estratégias de desfolhação.

\section{CONCLUSÕES}

Em dosséis de Urochloa brizantha cv. Piatã, a produção de forragem é maior com o manejo caracterizado por altura pós-corte de $20 \mathrm{~cm}$ e interrupção da rebrotação quando o dossel alcança interceptação máxima de luz, com pouca variação da composição morfológica do estrato de forragem colhido.

\section{REFERÊNCIAS}

BARBOSA, R.A.; NASCIMENTO JÚNIOR, D.; EUCLIDES, V.B.P. et al. Capim- tanzânia submetido a combinações entre intensidade e frequência de pastejo. Pesqu. Agropecu. Bras., v.42, p.329-340, 2007.

BORGES, B.M.M.N.; NOGUEIRA, M.; CAETANO, L.; LUCAS, F.T.; JESUS, W. Relationship between luminous flux intercepted at different times in leaf area index of different forages. Semin. Ciênc. Agrár., v.32, p.1589-1594, 2011.
BROUGHAM, R.W. Effects of intensity of defoliation on regrowth of pasture. Aust. J. Agric. Res., v.7, p.377-387, 1956.

CARNEVALLI, R.A.; SILVA, S.C.; BUENO, A.A.O. et al. Herbage production and grazing losses in Panicum maximum cv. Mombaça under four grazing managements. Trop. Grassl., v.40, p.165-176, 2006.

CARVALHO, F.L.; MEZZALIRA, J.C.; BREMM, C.; GALLI, J.R.; GREGORINI P. Effect of sward surface height and level of herbage depletion on bite features of cattle grazing Sorghum bicolor swards. J. Anim. Sci., v.91,; 4357-4365, 2013.

CHAPMAN, D.F.; LEMAIRE, G. Morphogenetic and structural determinants of plant regrowth after defoliation. In: BAKERS, M.J. (Ed.) Grasslands for our world. Wellington: SIR Publishing, 1993. cap.3, p.55-56.

DIFANTE G.D.S.; NASCIMENTO JÚNIOR D.; EUCLIDES, V.P.B.; SILVA, S.C.; BARBOSA, R.A.; GONÇALVES, W.V. Sward structure and nutritive value of tanzania guineagrass subjected to rotational stocking managements. Rev. Bras. Zootec., v.38, p.9-19. 2009b.

DIFANTE, G.S.; NASCIMENTO JÚNIOR, D.; EUCLIDES, V.P.B. et al. Ingestive behaviour, herbage intake and grazing efficiency of beef cattle steers on Tanzania guineagrass subjected to rotational stocking managements. Rev. Bras. Zootec., v.38, p.1001-1008, 2009a.

DURU, M.; DUCROCQ, H. Growth and senescence of the successive grass leaves on a tiller. ontogenic development and effect of temperature. Ann. Botany, v.85, p.635-643, 2000.

EUCLIDES, V.P.; EUCLIDES, B.; MONTAGNER, D.B.; BARBOSA, R.A. Manejo do pastejo de cultivares de Brachiaria brizantha ( Hochst ) Stapf e de Panicum maximum Jacq. Rev. Ceres. v.61, p.808-818, 2014.

GIACOMINI, A.A.; DA SILVA, S.C.; SARMENTO, D.O.L. et al. Growth of marandu palisadegrass subjected to strategies of intermittent stocking. Sci. Agric., v.66, p.733-741, 2009.

KÖPEN, W. Climatologia. Buenos Aires: Gráfica Panamericana, 1948. 
LACA, E.A.; LEMAIRE, G. Measuring sward structure. In: T'MANNETJE, L.; JONES, R.M. (Eds.). Field and laboratory methods for grassland and animal production research. Wallingford: CABI Publishing, 2000. p.103-121.

LITTEL, R.C.; MILLIKEN, G.A.; STROUP, W.W.; WOLFINGER, R.D. SAS system for mixed models. Cary, SAS Institute, 1996, 633 p.

MONTAGNER ,D.B.; VILELA, H.H.; SOUSA, B.M.D.L.; EUCLIDES, V.P.B. et al. Tillering dynamics in pastures of guinea grass subjected to grazing severities under intermittent stocking. Rev Bras Zootec., v.41, p.544-549, 2012.

NANTES, N.N.; EUCLIDES, V.P.B.; MONTAGNER, D.B. et al. Desempenho animal e características de pastos de capim-piatã submetidos a diferentes intensidades de pastejo. Pesqui. Agropecu. Bras., v.48, p.114-121, 2013.

PEDREIRA, B.C.; PEDREIRA, C.G.S.; SILVA, S.C. Estrutura do dossel e acúmulo de forragem de Brachiaria brizantha cv. Xaraés em resposta a estratégias de pastejo. Pesqui. Agropecu. Bras., v.42, p.281-287, 2007.

RIBEIRO, A.C.; GUIMARÃES, P.T.; ALVAREZ, V.H. (Eds.). Recomendações para o uso de corretivos e fertilizantes em Minas Gerais: $5^{\mathrm{a}}$ aproximação. Viçosa, MG: UFV / CFSEMG, 1999. 359p.

SAS Institute Inc. (1990) SAS/STAT(r) 9,0 User's Guide. SAS Institute Inc., Cary, 1-7886.
SBRISSIA, A.F.; SILVA, S.C. Compensação tamanho/densidade populacional de perfilhos em pastos de capim-marandu. Rev. Bras. Zootec., v.37, p.35-47, 2008.

SBRISSIA, A.F.; SILVA, S.C. O ecossistema de pastagens e a produção animal. In: REUNIÃO ANUAL DA SOCIDADE BRASILEIRA DE ZOOTECNIA, 38, 2001, Piracicaba. Anais... Piracicaba, SP: Sociedade Brasileira de Zootecnia, 2001. p.731-754.

SILVEIRA, M.C.T.; SILVA, S.C.; RODRIGUES, C.S.; LIMÃO, V.A. Herbage accumulation and grazing losses on mulato grass subjected to strategies of rotacional stocking management. Sci. Agric., v.70, p.242-249, 2013.

SISTEMA brasileiro de classificação de solos. Brasília: Embrapa, 1999. 412p. (Produção de Informação).

SOUSA, B.M.D.L.; NASCIMENTO JÚNIOR, D.; RODRIGUES, C.S. et al. Morphogenetic and structural characteristics of xaraes palisadegrass submitted to cutting heights. Rev. Bras. Zootec., v.40, p.53-59, 2011.

TAIZ, L.; ZEIGER, E. Fisiologia vegetal. 4.ed. Porto Alegre: Artmed, 2009. 819p

WOLFINGER, R.D. Covariance structure selection in general mixed models. Communications in Statistics Simulation and Computation, v.22, p.1079-1106, 1993. 